\title{
"All these worlds are yours except ...": Science fiction and folk fictions at NASA
}

\author{
JANET VERTESI ${ }^{1}$ \\ PRINCETON UNIVERSITY
}

\begin{abstract}
Although they command real spacecraft exploring the solar system, NASA scientists refer frequently to science fiction in the course of their daily work. Fluency with the Star Trek series and other touchstone works demonstrates membership in broader geek culture. But references to Star Trek, movies like 2001 and 2010, and Dr. Strangelove also do the work of demarcating project team affiliation and position, theorizing social and political dynamics, and motivating individuals in a chosen course of action. As such, science fiction classics serve as local folk fictions that enable embedded commentary on the socio-political circumstances of technoscientific work: in essence, a form of lay social theorizing. Such fiction references therefore allow scientists and engineers to openly yet elliptically discuss their social, political, and interactional environment, all the while maintaining face as credible, impartial, technical experts.
\end{abstract}

\section{Keywords}

science fiction; politics of science; lay sociology

\section{Introduction}

Planning for NASA's new mission to Jupiter's moon Europa is underway at the Jet Propulsion Laboratory (JPL), a Caltech facility near Los Angeles that operates contracts for robotic spaceflight. Based in a recently-opened building that is all concrete, steel and turquoise glass, the floor that houses the nascent project is a modern open office with beige cubicles, blonde wood conference tables, and brushed metal door signs. Early in the summer of 2016, I walk into one of the offices that ring the open floor, set down my bag and bring out my notebook in preparation for a meeting with the mission's chief scientist. It has been over a decade since I first began studying planetary scientists and their robotic operations on other worlds, and this moment marks a transition in studying my third mission team as an embedded laboratory ethnographer. ${ }^{2}$

\footnotetext{
Janet Vertesi, Email: jvertesi@princeton.edu

2 This paper draws on ethnographic work conducted with the Europa mission between 2015-2017, including onsite experiences at the Jet Propulsion Laboratory between 2016-2017. I attended project science meetings, from semi-annual gatherings of the entire team of $150+$ scientists to small, weekly meetings among core science staff. I conducted 30 recorded interviews and visited affiliated laboratories in three states. The Copyright ( 2019 (Janet Vertesi). Licensed under the Creative Commons Attribution Non-commercial No Derivatives (bync-nd). Available at estsjournal.org.
} 


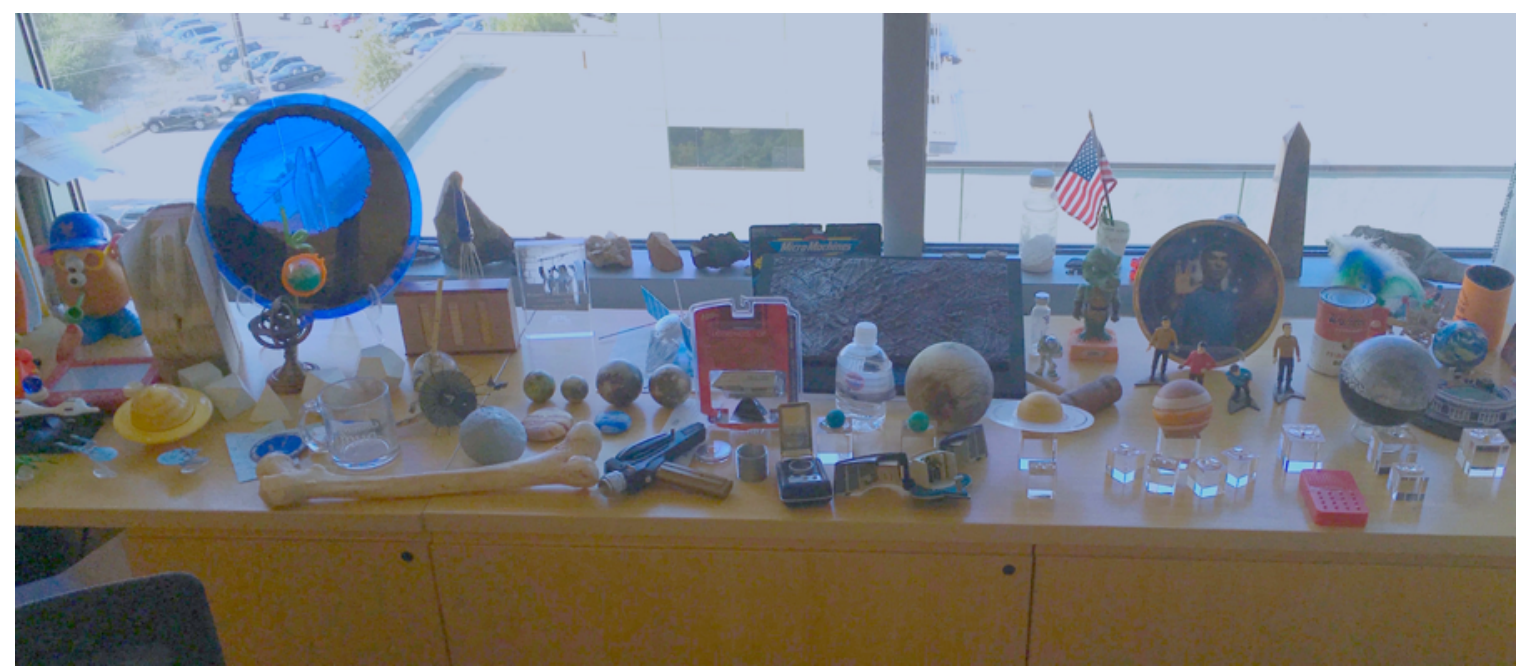

Figure 1: Real and fictional spacecraft decorate a scientist's desk on the mission, with a heavy emphasis on the Star Trek (the original series) universe. Author's ethnographic photo.

Looking around I note the diplomas and awards on the wall listing his membership in professional societies and congratulating him for his service to NASA. The countertop that extends from his desk across the window is littered with awards and models of the Galileo and Cassini spacecraft, both of which he has worked on. Nestled among these are models of the starship Enterprise in its various iterations over the course of the Star Trek series, figurines of its main characters Kirk, Sulu, Scottie, and McCoy, a model phasor and tricorder. A Spock commemorative plate sits next to a JPL achievement trophy, and a Barbie in an ensign's uniform stands guard over a stack of his published papers (Figure 1).

engineering team was not part of my analysis for the most part, although I maintained relationships with engineers on the Cassini mission. Because this was my third extended foray into the planetary science community, my relationships with community members were more extensive and bilateral than in past projects. I conducted at least 40 additional interviews with my recorder turned off, opting for extended field notes when these were extended conversations with individuals I have known in some cases for a decade. Team members also took photos or notes for me and sent them by email if I was co-present but recording video at the same time, or if I was in another meeting but they thought the moment would be of interest to me. I include a few of these observations and photos here as they demonstrate my relations with the site (they also offered better resolution, composition and lighting than my own photos!). When asked, I offered advice from the literature in team communication and organization, as I describe in the story with the Klingon analogy. This included running a Social Science Journal Club with about twenty team members who read articles from sociology, STS and CSCW. My own contributions were analogized through science fiction, with the chief scientist gifting me a Deanna Troy action figure upon my departure. Because I circulated this paper and discussed it in advance with a few members of the community, my findings may have influenced the fieldsite as well. For instance, after I departed, the team debated how to refer to stages in their science planning processes under acronyms that, when spoken aloud, sounded like Kirk, Spock, and McCoy. 


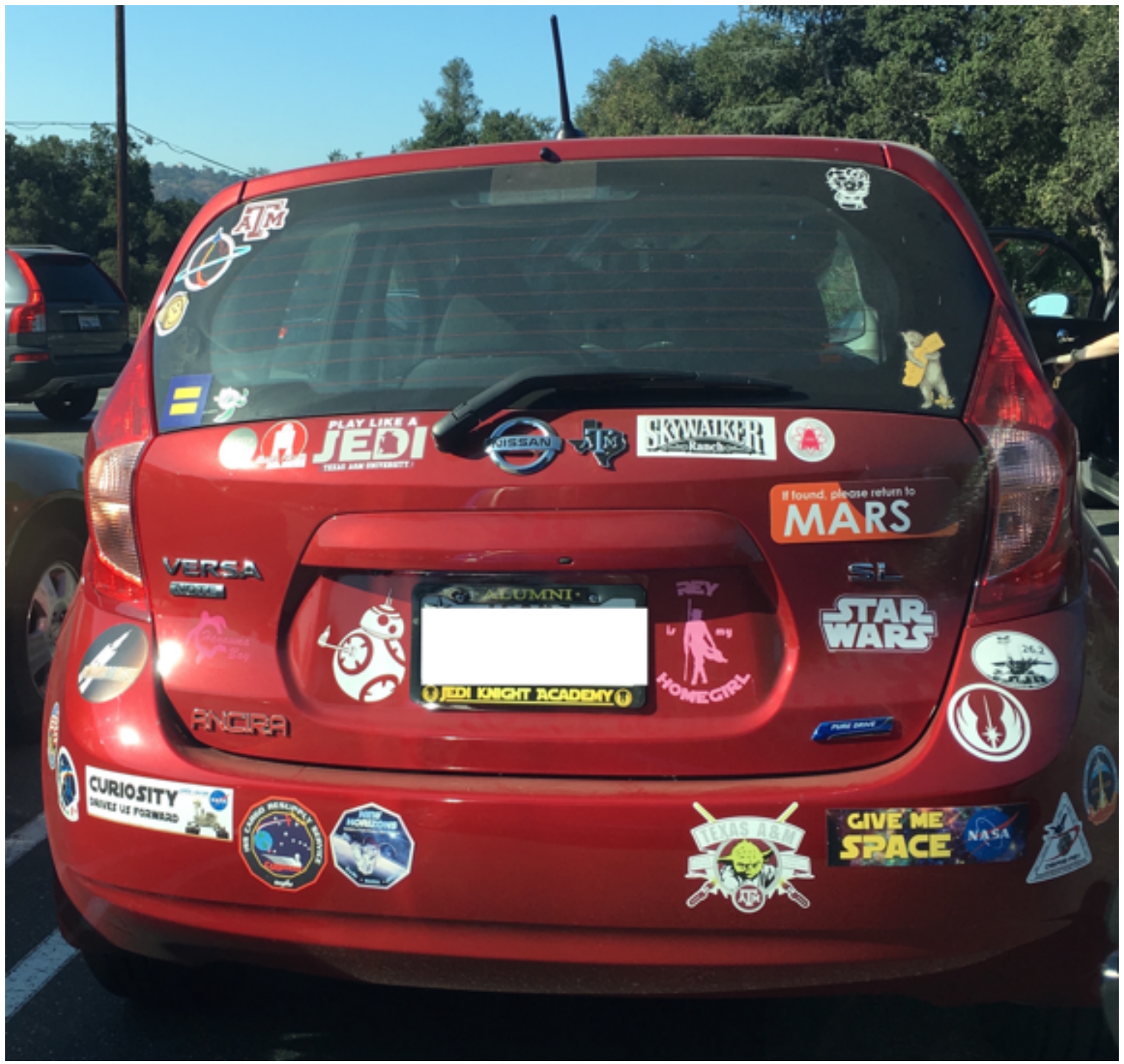

Figure 2: Bumper stickers and decals mix science fiction spacecraft with real spacecraft that the driver of this vehicle has commanded. Author's ethnographic photo.

This scientist is by no means alone. Walking down the corridor, the desks of other mission team members are decorated with photographs and emblems of NASA missions in the solar system, tacked to the wall alongside movie posters for the remake of Star Trek and the Kubrick film sequel 2010: The Year We Make Contact. I recognize scale models of fictional spacecraft perched next to 3D printed models of their orbiter and lander, still in development for their trip to Jupiter's moon Europa. On one scientist's desk is a model of the Apollo lander; the engineer in the cubicle across 
the way displays a scale model of a Romulan Warbird from Star Trek: The Next Generation. I witnessed similar styles of décor in my prior visits to dozens of institutions affiliated with the missions teams I have studied, and while conducting over one hundred interviews with planetary scientists and space engineers across the United States. Even in the lab's parking lot, bumper stickers place logos for real missions like Curiosity or Osiris-Rex next to images of R2D2 and BB8 from Star Wars (Figure 2), with one notable suburban's decorative license plate holder reading "My other car DESTROYED ALDERAAN." These individuals are busy building and commanding real spacecraft in the solar system; one might easily believe the Enterprise or the Millennium Falcon to be among them.

Fluency with science fiction worlds certainly serves as a geek cultural identifier mark of a form of membership at NASA and at this lab. But this is not a paper about science fiction and geek culture; it is a paper about science fiction and lay sociology. In particular, it is about how science fiction stories are imported, whole cloth, into techno-scientific communities as a way of accounting for organizational action and for sociotechnical relations. Community members' sense-making devices and cautionary tales are not taken from experience or from historical examples, from philosophies of ethics or from business school cases. Instead they draw from fictional narratives and characters that members of their community know and recognize from popular media, which they use to interpret and inspire local practical action. As such, members of this scientific community rely upon examples recognized from a shared cultural landscape in order to articulate the managerial, interpersonal, and workplace tensions and trade-offs associated with the human side of science and engineering, as well as to tie technical questions on the micro level to macro political concerns and national priorities.

This convergence points to new perspective on the role of science fiction in technoscientific communities on the one hand, as well as to the importance of analyzing scientists' local theories of human and organizational action on the other. In the following section, I describe these literatures and their contribution to the analysis that follows. I then describe the field site for my ethnographic work, including a review of the chief fictions that are part of everyday conversation and laboratory life. Next, I draw on two years of ethnographic fieldwork with a single spacecraft team to show how fictional tales are woven into the fabric of the mission in three ways: as a marker of membership, as a reference point for problem solving, and as an orientation toward action. This threading-through of scientific and technical work with references to science fiction provides a shared vocabulary for discussion of-and pragmatic orientations to action within-the acknowledged political complications of scientific and technical work.

\section{Science Fiction, Lay Theorizing, and Folk Fiction}

Science fiction is a familiar topic for science studies scholarship. A common stream of work draws upon critical theory to analyze specific movies or series, offering close readings in historical context to better understand social or technical issues of the day, such as the relationship between machines and social relations, gender, embodiment or virtuality (Balsamo 1996; Edwards 1997; Hayles 1999). Cultural critics unearth the politics, feminist, and racialized visions of utopian and dystopian 
futures (Goodwin 1988; Shaw 2000; Jameson 2005; Benjamin 2018), including new readings of popular narratives about space exploration (Penley 1997). Scholars also bring science fiction tropes into academic discourse, as in Donna Haraway's imported figure of the cyborg-itself arising from the science of cybernetics--which reminds science studies scholars of the entanglement of seemingly dichotomous categories (Haraway 1991).

More recently, science fiction has garnered interest among science studies scholars as a site that grounds various forms of situated futures, whether in the "visioneers" who contribute to the development of space capabilities (McCray 2012) or the practical relationships between film producers and science advisors that make "diegetic prototypes" of futuristic tools appear plausible on-screen (D. Kirby 2010; D. A. Kirby 2011). Comic book fictions and fantasies illuminate studies of nanotechnology and its imagery (Milburn 2008), while classic science fiction series give rise to familiar devices in the world of personal and ubiquitous computing (Dourish and Bell 2014). As these analysts explain, science fiction is a way of making visible and ultimately enacting specific futures: building bridges between visionary techniques and technical work while inspiring those who read or view such media to build (or purchase) the next generation of tools in that image. Such accounts are important ways of understanding the value and seriousness of science fiction as a cultural artifact, particularly in the formulation of shared sociotechnical imaginaries that unite nations behind big science projects (Jasanoff and Kim 2015), or in the production of speculative fictions that invite us to imagine a more just society (Benjamin 2016).

Despite the US space agency's tremendous importance in articulating a national agenda for exploration and colonization, the above approaches to science fiction did not capture what I observed on the ground when NASA-employed scientists and engineers invoked well-known visions of the future. Instead, I found it more useful to address meaning-making with science fiction on the ground within scientific communities: as Colin Milburn puts it, the question of "science fiction at the bench" (Milburn 2010). My questions in this paper therefore address this sensibility toward science fiction in action, investigating how scientists and engineers put their familiarity with specific science fiction universes to work in professional settings. After all, it is well known among scientists and engineers that science fiction is a vehicle for social commentary, but it is an open question as to how these communities read and actualize science fiction in this way, and how they put these lay literary interpretations to use in their work. For instance, Milburn's extended study of nanotechnologists demonstrates how scientists appropriate science fiction narratives to situate their own contributions and their futurist possibilities (Milburn 2010, see also 2008). Also at NASA, Zara Mirmalek describes how those who worked on the Mars Exploration Rover mission drew on popular media representations of devoted workers and heroic space pioneers to narrate their difficult experiences of "Mars Time" as a question of personal sacrifice and identity instead of organizational failure (Mirmalek 2009). Like these scholars, I look to the settings of techno-scientific work to see how members' understandings of science fiction circulate among social groups, and how experts deploy these understandings to solve problems.

Rather than solving "purely" technical problems, however, I am concerned here with a different form of sense-making among scientists: about organizational practices, human interactions, politics, and organizational behavior. In short, I am interested in how science fiction 
is enrolled in scientists' forms of lay social theorizing. Lay expertise has long been a subject of study in STS (Wynne 1992; Prior 2003; H. M. Collins and Evans 2002; Epstein 2007), especially with respect to medical sociology and non-compliance (Prior 2003; Benjamin 2011), yet lay understandings of social action also undergird interactional environments, including among scientists. For instance, "lay sociology" forms the core of Garfinkel's investigation of ethnomethodology, which seeks to understand members' shared forms of situated sense-making and accounting for practical action (Garfinkel 1967; Garfinkel, Lynch, and Livingston 1981; Lynch 1993; Coulon 1995). While members of a community are not passive "judgmental dopes"(Garfinkel 1967, 68), or pragmatic problem-solvers who wield a cultural "toolkit" for addressing social problems (Swidler 1986), they do conduct active sense-making with materials that are ready-tohand. As such, science fiction narratives, situations, and characters provide fodder for theorizing and communicating about human behavior. Like the "folk theories" that Arie Rip describes in nanotechnology--shared narratives that "frame views and inform an action perspective" (Rip 2006, 361; see also Simakova 2012) —references to mass media representations serve as a local shorthand that relays members' organizational intuition about a problem at hand.

This is important because many layers of institutional conflict and politics suffuse this site. There are the challenges of requesting Congress fund the mission and maintaining the flow of money despite government shut downs and continuing resolutions. NASA itself is also a heterogeneous institution, leading to challenges such as negotiating with vendors, integrating the development of nine instruments across several different institutional boundaries, building a spacecraft that will not interfere with those instruments' functioning (McCurdy 1994; Vaughan 1997), and avoiding setting off any "personalities" (Vertesi 2020, forthcoming). Even among the rank and file, scientists and engineers were well attuned to these machinations, often pointing out the complex backgrounds to these interactions to me during meetings with the explanation that "there is a lot of sociology in this room." Although they sought to minimize the effects of such machinations on local decision-making, I was often reminded of Gabrielle Hecht's surprising interview with a senior manager at a technical facility in France who explained with gusto that all of their technical decisions were in fact political decisions (Hecht 1998, 56).

I describe these lay social theories as folk fictions to emphasize how science fiction narratives provide repertoires that articulate lay sociological principles and project capabilities for action. As a form of lay sociology, they present both a perspective on the current moment as well as an implied or expected course of action or strategic path for involved actors: an "orientation for future action" (Rip 2006, 349). But while nanotechnologists' folk theories are based on scientists' interactions with various publics to explain "how science works, how technology develops, how public(s) behave" (Rip 2006, 361), folk fictions are imported from fictional universes whose characters and situations are well known to members of the scientific community. Unlike organizational fictions, which everyone in the organization knows but no one believes (Stanley 1966), these folk fictions are ethnomethods-members' sense-making devices that import both a narrative framework from science fiction and shared knowledge of how the story ends (including a relevant "moral of the story") to locally articulate social tensions at the same time as accounting for future action (Garfinkel 1967). Thus, much like Katie Shilton's "values levers" (Shilton 2013; see 
also Steen 2015)--occasions within an engineering team where it is sanctioned to deviate from progressivist or technical talk to discussion about non-technical values embedded in design decisions-references to these known stories provide occasion for a departure from technical or scientific problem solving toward reflection, commentary, or leverage upon the sociopolitical elements in the room.

\section{Science Fictions and Laboratory Life}

The coterie of planetary scientists and space engineers working together on the Europa mission are planning and assembling spacecraft for the exploration of Jupiter's ocean moon, planned to launch in 2023 and arrive at the moon later that decade. Over a hundred PhD-holding individuals employed at various research facilities across the United States are, at time of writing, busy formulating and building instruments and data management plans for observing Europa, including imaging, radar sounding, spectroscopy, particle analysis, and magnetospheric mapping. The science team is distributed across many universities and research centers and only meets face to face a few times per year, with regular contact by teleconference, WebEx, and occasional inperson meetings. Ages range from senior personnel in their fifties and sixties, to junior scientists and engineers in their thirties and early forties. Many of these individuals met in graduate school or shortly thereafter, and have been working on establishing this mission for decades.

Most of the American scientists I have interviewed across the planetary science field described being influenced in their career decisions by some form of science media, whether Carl Sagan's Cosmos series or images from Voyager or Viking in National Geographic. Many also described being avid science fiction readers during their childhoods. Authors like Clarke, Asimov, and Heinlein were frequent points of reference for older scientists; others pointed to Star Trek which piqued their interest in a vision of a peaceful future amid the stars led by science, prompting them to do their part to make these visions into a reality. Some scientists and engineers even serve as science advisors to television shows and films. For instance, the imaging leader on Cassini was an advisor to the Star Trek reboot; an engineer on that same mission advised the Battlestar Galactica series reboot; and two early career scientists on the Europa mission were credited advisors for the independent film, The Europa Report (2013).

This tight interconnection between planetary science and science fiction explains why, over my many years of working at NASA, I repeatedly witnessed elements of science fiction interlaced with science fact. Early patches for the Mars Rover mission feature the Loony Toons character Marvin the Martian in a salute; models of Marvin also sit next to scale models of spacecraft on mission desktops. At events to discuss the future of Mars exploration, science fiction authors such as Ray Bradbury and Kim Stanley Robinson are invited discussants at panels that placed them alongside scientists and engineers commanding rovers on Mars. Spacecraft team members regularly attend geek meet-ups such as ComicCon, DragonCon, and Star Trek conventions, sometimes speaking about their work on mission teams to crowded rooms of fans. Within the lab and beyond, with geek cultural icons from Star Wars to Doctor Who as well as online geek cultural artifacts like memes form the crux of community member jokes and insider cues. Even at the 
American Geophysical Union meeting in December 2016, a meeting for scientists involved in the Earth sciences and planetary exploration, "pods" that could be reserved for extended conversations were named sequentially after science fiction movie titles (i.e. "Rogue One" or "Fifth Element") with the expectation that everyone would be in on the joke. This included knowing that "Wrath of Khan" and "Return of the Jedi," although not containing any overt numbers, referred to the second and sixth pods in the row due to the films' position in their respective series.

On the one hand, fluency with these terms serves as a general cultural signifier: a sign of membership in broader "geek culture." While it was once a stigma among young people, the rise of "geeks" in the financially-saturated industries of Silicon Valley has made geekdom in the early twenty-first century a sought-after and hotly contested category. Already on the rise in the United States among middle class, technically educated elites, being a geek brings higher social status among a technocratic community. Thus sorting out real geeks from fake geeks (including fake geek girls: see (Varma 2007)) is an ongoing discussion in online forums, at geek conventions such as ComicCon, even in psychological literature (McCain, Gentile, and Campbell 2015). Being well versed in a collection of television shows, movies, novels and comic books gives "geek cred": the ability to show membership in this elite group. NASA scientists and engineers-largely white, middle class, well educated, and with a high ratio of men to women-certainly fit this mold.

On the other hand, elements of specific science fiction pieces are put to work in specific ways among local micro-cultures on the ground. Here fluency in particular science fiction universes demonstrates fluency in the language of the local techno-scientific project, and provides a backdrop of experiences and reference points that individuals draw upon to identify and resolve "social" or "political" problems in their midst. As a methodological note, I found I was often less stymied by technical or scientific details discussed in the site than by grasping the nuance of these specific references. Although I spent my childhood steeped in the Star Wars and Star Trek: The Next Generation universes, this was not enough. I began to watch these movies and television series systematically as part of my fieldwork to grasp the depth and scope of references that suffused the environment around me.

\section{The Fictions}

On the Europa mission in particular, members are partial to references to the original Star Trek series, the 2001 and 2010 films, and, to a lesser extent, Dr. Strangelove Or: How I Learned to Stop Worrying and Love the Bomb. Although mission development began during a period of relative peace and international collaboration, it is interesting to note that these examples are cold war dramas that offer specific perspectives on political and interpersonal conflict and its resolution. By means of a brief introduction, Star Trek places a multi-racial crew of humans and a half-alien aboard the intrepid Starship Enterprise whose mission is to "boldly go where no man has gone before." An ensemble cast par excellence that aired on television from 1966-1969 and later featured a series of movies in the 1980's and 1990's, the Enterprise's crew encounters alien races and strange phenomena in space that they use science, reason, logic, and human intuition to collectively and peacefully overcome. Star Trek's collective approach and common-sensical decision-making 
contrasts with the ironic comedy, Dr. Strangelove, which premiered in 1964 (Kubrick 1964). The movie features a rogue general who sends a bomber into Russia, with the President and his advisors unable to stop them; this forces the deployment of Russia's massive nuclear arsenal ("the Doomsday device") that brings on the assumed end of the world. 2001 and 2010 are based on novels by Arthur C. Clarke, with initial screenplay co-authored with Stanley Kubrick and the sequel adapted by Peter Hyams (Clarke and Kubrick 1968; Hyams 1984). 2001: A Space Odyssey, released in 1968, introduces a mysterious monolith in the Jupiter system with unusual properties that an American spacecraft goes to investigate, leading to the revolt of their on-board computer system and the loss of all crew except one, who is absorbed into the monolith (Kubrick 1968). In 2010: The Year We Make Contact, released in 1984, the monoliths are revealed to be life-generating and protecting, ultimately fostering photosynthetic life on Europa. A joint American-Russian mission returns to the planetary system to solve the mystery. As Jupiter implodes into a new star and their craft races to safety, the monolith transmits a message to their ship: "ALL THESE WORLDS ARE YOURS EXCEPT EUROPA. ATTEMPT NO LANDING THERE” (Hyams 1984).

Each fictional universe demonstrates a different relationship between politics and decision-making. In Star Trek, conflict is resolved through educated people working together creatively to solve problems. They draw upon scientific and technical facts and upon human intuition and emotions to work together. The Enterprise's core crew are fast friends, with the relationship between Captain Kirk and his first officer Spock especially poignant; in subsequent films these friendships far outweigh personal and professional duties, leading the crew to perform feats that would otherwise be outlawed by their Starfleet (Nimoy 1984). Trust, relationships, and the considered balance of expertise are the order of the day. This is all the more important given that central crew members are female, African-American, Russian and Japanese, the latter being recent enemies of the United States and the former struggling for recognition in the civil rights movements of the era. The assumption is that man- and woman-kind on Earth live in harmony and equality in a 1960's liberal vision of a utopian future (O'Connor 2012).

By contrast, trust is tenuous and Earthly politics looms large in 2010. Three Americans hitch a ride on a Soviet spacecraft to Jupiter. The Soviets distrust the Americans although they need them to complete their mission, and the lead American scientist exhorts them to consider science, not politics. Meanwhile, on Earth, a hot-headed President leads into a face-off over a nuclear blockade with Russia in Central America. The crew must build trusted relationships as they undertake dangerous feats, by learning the basics of each other's languages, for instance. But this is set against the background of disintegrating diplomatic ties between their two countries on Earth. Although they are all attempting to survive and return home, allegiances are ambiguous.

Finally, decision-making in Dr. Strangelove is farcical. A deranged general decides to singlehandedly provoke nuclear war in response to water fluoridation, which he suspects is a Russian plot. His comedic counterpart in the President's coterie, with a thick Southern accent, and the cowboy Major Kong, who pilots the bomb to its target, speak to classic divides in American politics. The President himself is incapable of effecting any power. The Russian diplomat reveals as much insanity on the Soviet side in their attempts to "keep up [with] the arms race, the space race, and the peace race." Dr. Strangelove, the President's technology advisor, is a mad scientist with hints 
of a German military past, much like the rocket and nuclear bomb designers brought to America from Germany during and after WWII. The movie closes with Major Kong riding the bomb like a steed as it falls over Russia, waving his cowboy hat. Through a combination of untrustworthy superiors, ineffective hierarchical command, and American hubris the world goes up in nuclear flames. In Strangelove people are fragmented, insane, and incapable of communicating effectively. Opposing sides cannot even begin the process of finding common ground.

There are of course many science fiction touchstones in geek culture as well as at NASA that enter popular discourse, and other missions embrace other metaphors and storylines as their own. Below I will discuss situations where elements of these particular science fictions come into play in the room as folk fictions, as scientists discuss the possibilities for their forthcoming mission to Europa with full recognition of the inter-institutional and political challenges that they face.

\section{Folk Fictions as Assertions of Membership}

Most of the moments where science fiction made an appearance in the laboratory were mundane. Individuals within different missions wore clothing and other tokens related to these and other beloved series, often mixed together. In a meeting of another mission's team that I joined regularly, a senior engineer showed up in a Star Trek: Voyager fleece thrown over a Star Wars T-shirt; at other times, she sported a Star Wars BB8 bomber jacket (Figure 3). Down the hall, a mission planning whiteboard sported a quote from a colleague--“'You haven't had that trouble with your Death Star, have you?"--right across from a posted list of the top 100 science fiction books of all time, upon which mission members were entreated to mark which ones they had and had not yet read. Two senior engineers at this meeting attended fan conventions regularly, planning their attendance months in advance. They agreed that although you used to not be able to like both Star Trek and Star Wars at the same time (like the Yankees and the Red Sox, a secretary in the room offered by means of translation, otherwise baffled by the admiration for these series and the encyclopedic knowledge of them on display by her colleagues), everyone now had "outgrown" that, perhaps indicating the importance of demonstrating knowledge of elements of geek culture more broadly. "I've never felt the need to apologize for what I like," claimed another. 


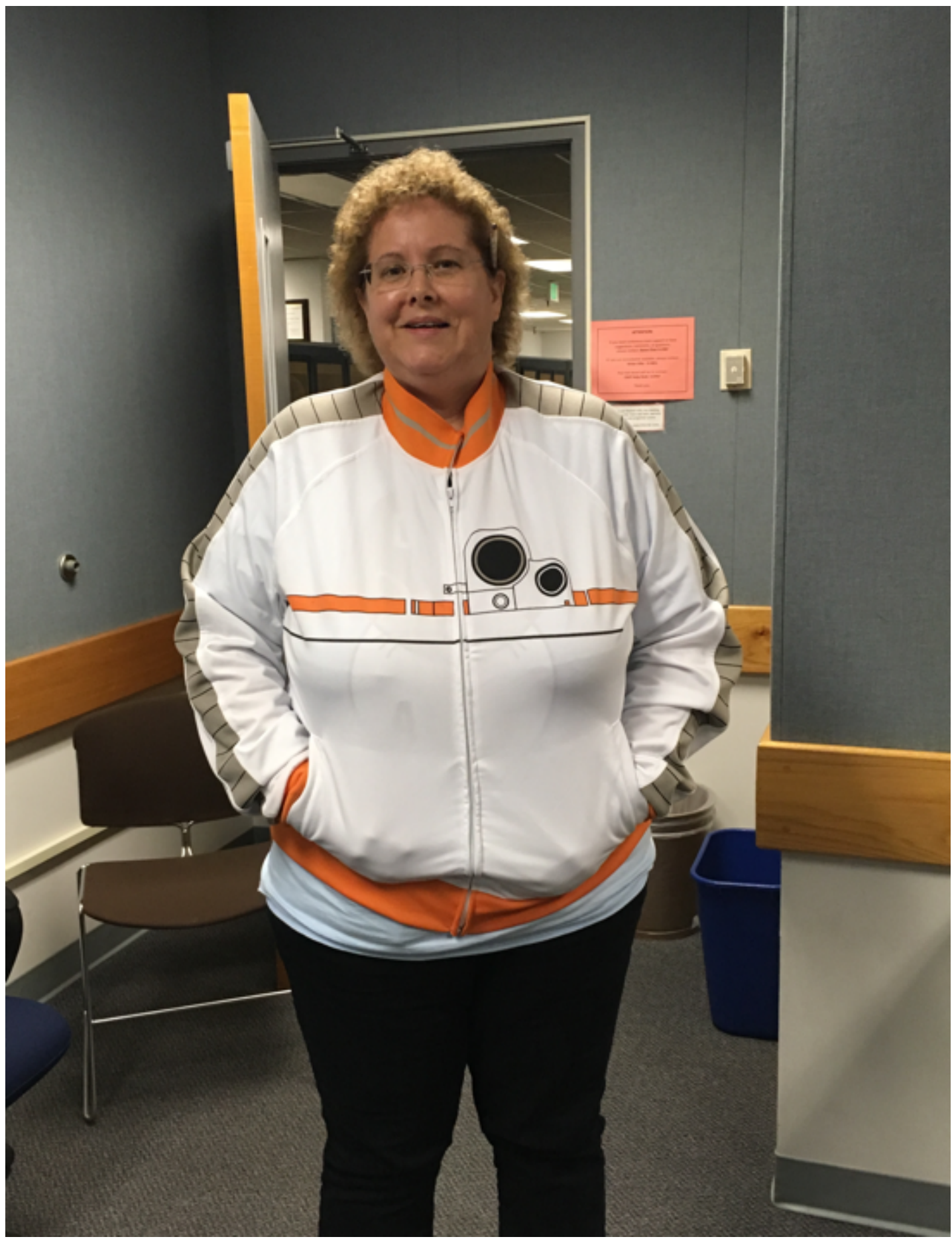

Figure 3: A mission engineer sports a Star Wars BB8 bomber jacket at work. Author's ethnographic photo. 
Alongside these tokens, references to certain science fiction series were brought into conversation at meetings, generating laughter over a common reference point to explain the work at hand. For instance, I joined an early face-to-face meeting of a group of scientists tasked with formulating a lander to work on Europa's surface. These scientists had experience working on the surface of Mars as well as orbital expertise gleaned from studying the outer solar system's icy moons. Members of these two communities knew each other by reputation but had not necessarily met in person before. Before the second day of their meeting people in the room chatted as the video conference system was loading. Talk turned to a recent discovery announced by a space telescope team, of another planet with Earth-like conditions located millions of miles away in a different solar system. When someone misheard that a colleague in the room was planning a mission there for the next funding cycle, he quipped, "It would certainly take an ion propulsion drive to get there." This joke referenced at once an obscure Star Trek technology (futuristic even for the Enterprise's chief engineer), a recent well-publicized scheme to turn this technology into reality among engineers at a competing NASA center, the scientists' general skepticism that this technology could ever be made a reality, and the fact that many of the scientists in the room were already in competition for this next grant. The comment elicited group laughter and contributed to the sense of solidarity in the room among a newly forming team.

Reference to shared science fiction elements can also serve to orient the mission at the outset. At the first Europa Ocean Conference in 1996, a team member reportedly asked Arthur C Clarke, the author of 2001 and 2010, to join them on a teleconference call. They were anxious for his blessing for their mission to Europa given the dooming statement at the end of the film: "All these worlds are yours except Europa; attempt no landing there." Once they received his official pardon, it was alright to proceed. The scientists who told me about this event, it seemed to me, were only partly joking.

2001 plays an important role on the Europa mission more generally with respect to team solidarity. Inspired in part by sociological study of an earlier mission (Vertesi 2015), the chief scientist of the Europa team decided that it was important to develop rituals to bring the team together. His solution was to hire a local Hollywood set builder to build a nine-foot tall scale model of the 2001 monolith (Figure 4). At the beginning of the first meeting of the entire science team as the mission got its start, the lights went off in the room and the iconic opening music from 2001 filled the air. On the presentation screen at the front of the room was the dramatic moonrise from the movie. The scientists in the room laughed, catching the reference to the film and its association with Europa. As the music swelled to a crescendo a light dramatically illuminated the model monolith standing in the corner of the room. More laughter ensued. The chief scientist then walked down the aisle between seated scientists with a large bone in his hand, just like the one in the film, tapping it against his palm. He launched the bone toward the screen just as the scene cut to the great ape throwing his bone into the air. The scene cut again such that the bone immediately became the team's prospective spacecraft, soaring above their icy moon. The scientists and engineers in the room applauded and cheered. 


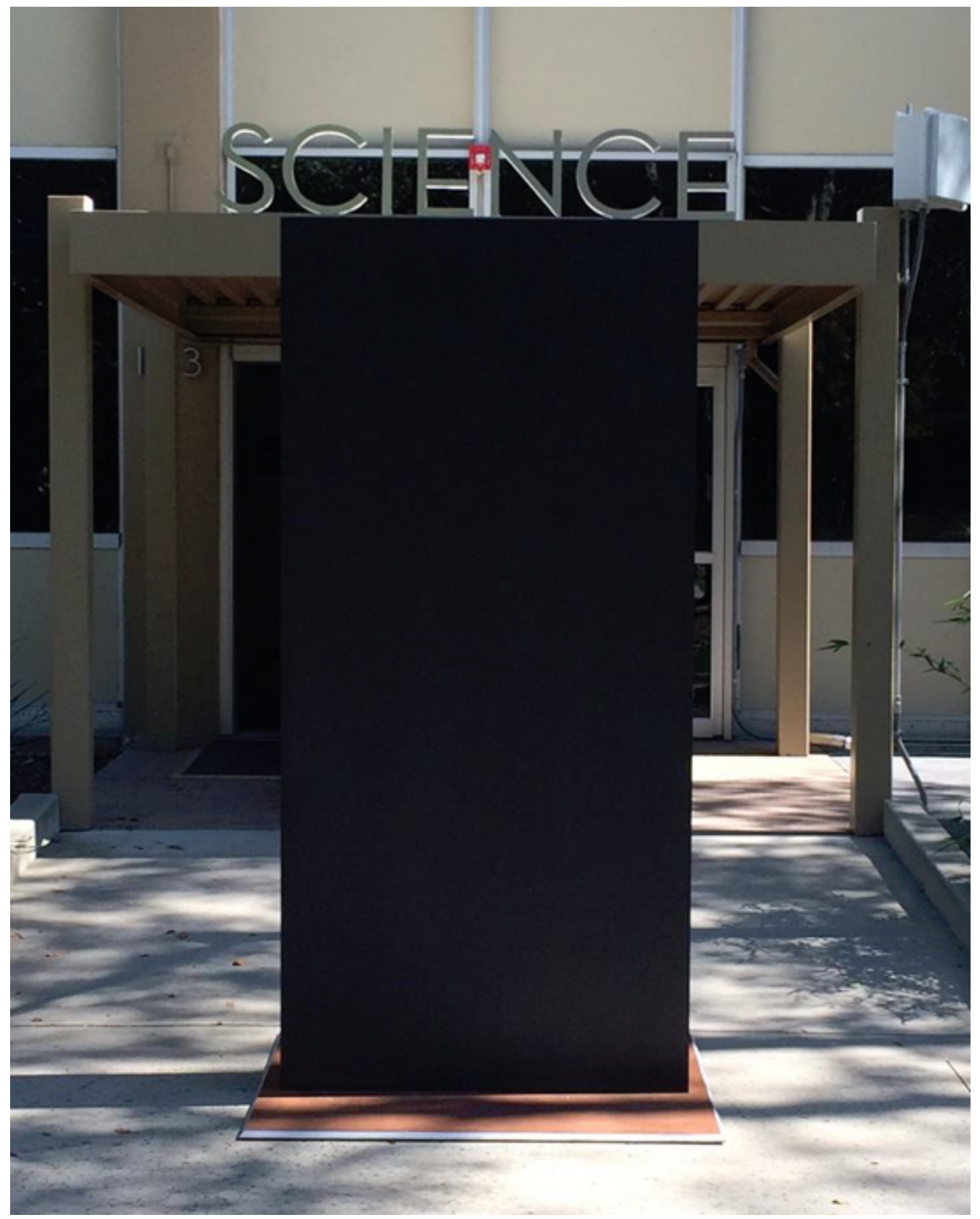

Figure 4: The Europa mission monolith outside the Science building at JPL, before its deployment at the project meetings, in July 2015. With permission of Robert Pappalardo. 


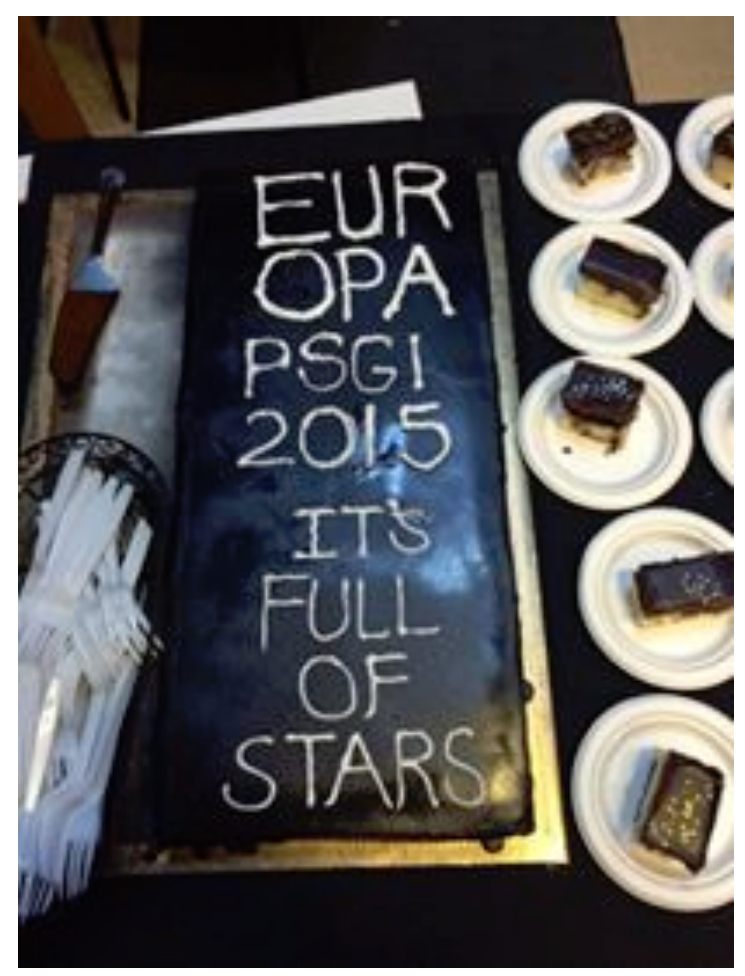

Figure 5: This celebratory cake at the inaugural science team meeting in the shape of a monolith bears a key quote from 2010. With permission of Robert Pappalardo.

When the lights came up, the scientist laid the bone on the podium. When mission members came up to speak throughout the day they picked it up as their turns arose and used it to gesture to their slides, or tapped it as they paced the front of the room. Everyone was issued tiny thumb-sized monoliths for people as tokens for their badge lanyards, the small black plastic brick featuring EUROPA printed on one side. The cake cut that evening to celebrate the start of the mission was a chocolate rectangular slab with the words "IT'S FULL OF STARS" scrawled on top, another reference to the monolith from 2010 (Figure 5).

As the mission monolith was dutifully rolled out for every project science group meeting at the lab it came to acquire a meaning of its own. When one meeting was held at a midwestern university, the students at the school built their own monolith outfitted with an Arduino-activated speaker such that when someone approached, the familiar opening theme of Also Sprach Zarathustra played aloud. At this the group joked about whether or not there was a line in the budget for moving the monolith around to meetings, or if local hosting groups would be asked to provide a monolith on their own dime (others were later built at participating facilities, leading to jokes about it reproducing much like in 2010). At another time I saw the bone used to approximate the spacecraft's planned orbital trajectory as it would eventually fly past Europa. The chief navigator, talking to a group of scientists at one of these meetings, picked up the bone, positioned it as if it were the spacecraft itself, and flew it carefully over a globe sitting at the front of the room, 
all the while referring to images of the moon's surface projected on the screen behind him upon which he had overlaid the planned trajectory (Figure 6). Thus the bone became the future spacecraft again, fusing science fiction imagery with the imaginary of the future craft at a moment of group entrainment and collective work (R. Collins 2004).

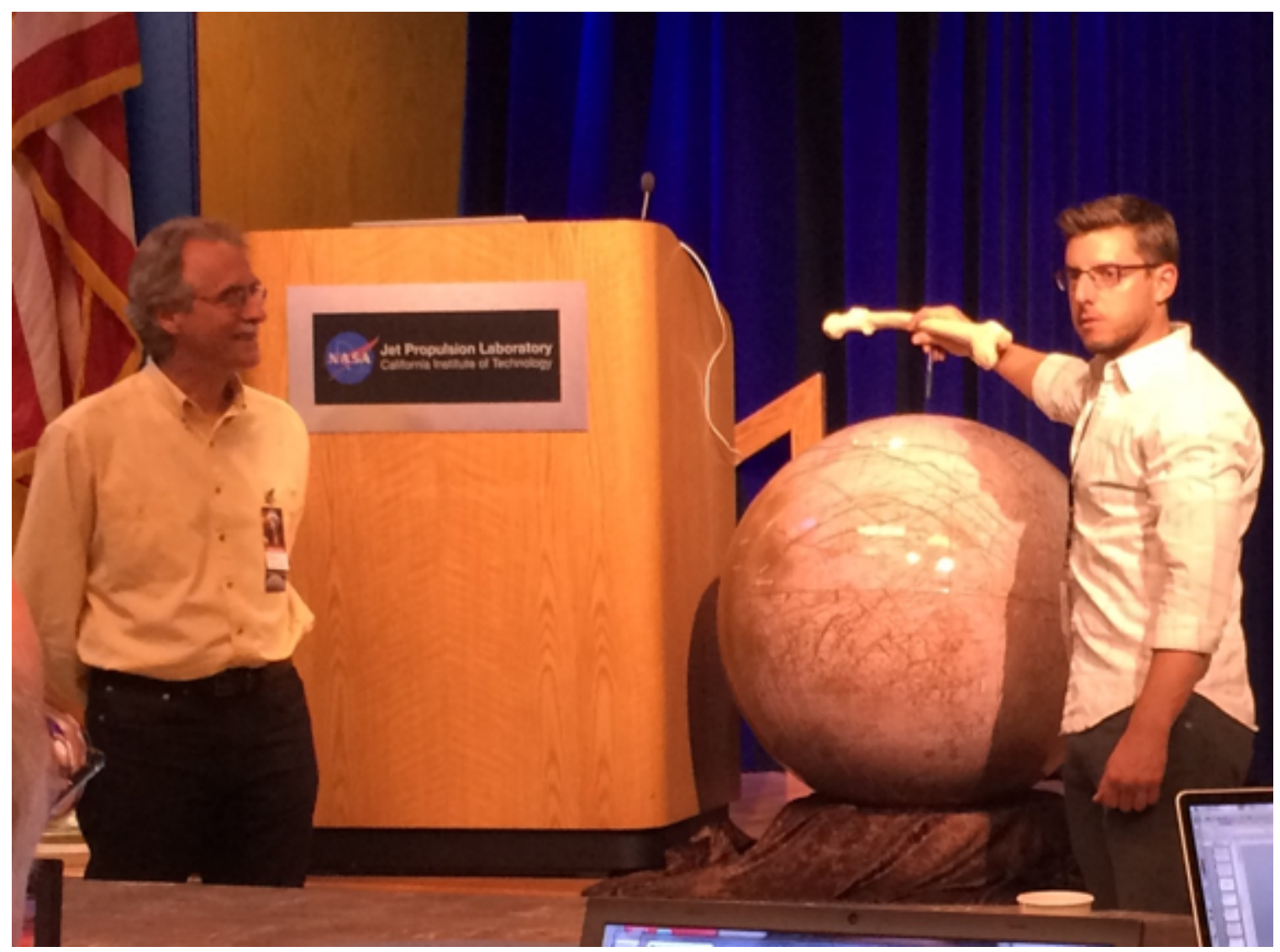

Figure 6: The mission design manager uses the bone and a Europa globe to demonstrate the spacecraft's trajectory with respect to the moon during flybys.

In this way the monolith and the bone gradually became familiar group tokens, part of the material culture of the mission. As they were visible during moments of mutual entrainment associated with group work they became early symbols of mission gatherings and participation. The project science office even founded an achievement award that they called "the Monolith Award," which they gave to senior scientists in their community to acknowledge their contributions. This included a trophy of a black plexiglass slab carried with white gloves to its awardee at an annual mission awards banquet. Producing local meaning around these symbols required drawing on considerable existing cultural cache among members in the room. That is, 
many scientists in the room recognized the monolith, the film sequences and lines, and their relationship to the moon the team was going to explore.

That such symbols serve as meaningful markers of group membership is especially evident when they are used incorrectly. For instance, references to Doctor Who--another staple of geek culture-are rare in Europa meetings, acknowledged with a gentle chuckle as membership in broader cultural trends, but not typically repeated by others across the team. In one meeting where someone was evidently going overtime presenting their slides, a staff member joked that they needed a Tardis, referring to the time travel phone booths on the show. The leader of the meeting stated that they should perhaps put a phone booth next to the monolith: this saved face in the awkward moment of only a few smiles in the room. But no Tardises appeared on the floor. Star Wars references on the mission were similarly few, although not entirely absent, and when I encountered them in other parts of the lab they felt like markers of being in a different place. It was only while talking to the engineer in her BB8 jacket on a different mission altogether that I felt like one of the team telling her about the model R2D2 on my office desk back home.

\section{Folk Fictions as Socio-political Commentary}

If the monolith came to be a marker of membership among Europa mission members, it also stood in for the political complexities of the search for life on Europa. In the film 2010, the monolith's presence at Europa catalyzes life on the moon's surface, and warns off the curious humans visiting from Earth. At early meetings of the Europa team, the group struggled with how to synthesize their own scientific investigations of the moon's surface-careful, pre-planned catalogues of observations-and the need to respond to an unexpected discovery, such as biological markers. Just as some joked occasionally about "seeing the whales" (both an impossible prospect and a reference to Star Trek IV), the monolith was also invoked as a symbol of this tension between exploration and discovery.

In particular, fluency with these cultural objects and their local signifiers also provided grounding for shared sense-making about the politics of the mission. Individuals made references to these films among their peers in order to comment on the sociopolitical situation in the room that suffused their local decision-making. Note that the joke about the ion drive was funny not just because it was a science fiction reference, but because it also spoke to the fierce competition for resources between different NASA centers and between the human and robotic spaceflight programs during a period of austerity, wherein the earnest work of one group could be seen as outlandish by another. Similarly, the extended joking about who would pay for the monolith took place against the background of the federal funding crunch; as the team was slashing its own scientific budget, who would foot the bill was a constant concern.

The monolith therefore illuminated another axis of tension on the mission. Congress specifically directed the Europa mission to search for life, or at least the conditions for life (as scientists put it, "habitability"--(see Helmreich 2009)), on the ocean moon. But technologies for life detection are non-existent, and planetary scientists since the Viking mission have been reticent to make such claims. Scientists were uncomfortable that life-detection might become one of the 
mission's top-level requirements, as it would be a requirement they could not guarantee they would meet. As such, the monolith also came to stand in for the possibility of a life discovery. As one scientist joked during an interview, if you didn't look carefully at all the images acquired by the orbiter, "you could totally miss the giant [alien] spacecraft sitting on the surface, right?" When the interviewer laughed, she followed up: "A monolith." In other moments during routine meetings, the chief systems engineer would caution his descriptions of how the mission would run with, "unless we see the monolith"--indicating that, in such a case, plans would rapidly change. Like the invocation of "dinosaur bones" on the Mars Rover mission--a mythical discovery of such obvious importance that the mission would stop in its tracks to investigate (Vertesi 2015) - the monolith became a symbol for of all that the Europa mission was hoping to find, as well as the political and scientific uncertainties surrounding its discovery.

Another long-running issue concerned how or whether the mission would sport a lander as part of its design. Although the lander was recommended by a panel in 2003, at a series of meetings in 2012, a group of scientists associated with the orbiter's science definition team stated that a lander would be unnecessary for achieving the primary science goals of the mission; these scientists were later selected to join the orbiter's science team. But political support from a Congressman added a federal mandate to include a lander to search for life. This was complicated not only because of the challenge of life detection, but also because the prior scientific panel, staffed with many individuals who later joined the orbital team, had recommended against a lander. Individuals who were unfamiliar with Arthur C. Clarke's pardon frequently commented on lander activities with the second half of the phrase from 2010--"Attempt no landing there"--a dual commentary on the social precariousness of the lander with respect to the orbiter, as well as on the perceived complications of developing a lander with political impetus but without the science community's full support.

The potential lander's political situation was subject to several of these wry comments. At a team meeting early in the mission, the scientists discussed how their orbiter might be used to carry the prospective lander to Europa. This would add mass and cost, and possibly cause a delay in the launch date. As the conversation went on a scientist sitting near me loaded an iconic screenshot from Dr. Strangelove on his laptop: Major Kong riding the bomb down to the Russian plains. He nudged his neighboring colleague and pointed out Kong as their patron and the surface as Europa. The analogy was that too much enthusiasm for a lander could lead Congress to ride a bloated mission down to the moon's surface, thus damning the whole enterprise. Of course, this was not an assured outcome: from another point of view, the lander's addition could ensure their mission's funding and survival. Regardless, as folk fictions, scenes like these from Strangelove and 2010 served as a means of social commentary on the mission's political predicament and its anticipated outcomes.

\section{Folk Fictions as Interactional Roadmaps}

When science fiction becomes folk fiction, it becomes a local shorthand to describe and explicate the politics and social behaviors involved in decision-making. But it also describes perceived 
eventualities, or articulates a course of action. For instance, in a discussion about how two different contractors were locked in argument, the lead system engineer reportedly explained that this was because "the face of one is white on the right side, and the face of the other is white on the left side." The reference is to a Star Trek episode in which the crew encounters two alien races locked in deadly battle over what is to them an irreconcilable difference: which side of their face is dark and which is light ("Let That Be Your Last Battlefield," aired January 10, 1969). The scientist who explained the reference to me glossed this as "a commentary on the apparent trivialities that can bring about hatred and war." But it was also a comment on the unlikelihood that the two contractors would ever reconcile their differences and see eye to eye, whether the group at JPL attempted to facilitate or not.

During another series of discussions about the degree of on-board automation on the spacecraft, references to 2001's HAL abounded as the science team attempted to explain their uneasiness with allowing machines to make decisions about how and when to plan scientific observations. At one point, the chief engineer even quipped, "As much as I'd like to send HAL to Europa...." Talk about HAL implied a course of action in achieving the balance between automated and human decision-making. Because HAL ends up murdering his crew members in dogged pursuit of his mission, this folk fiction reference helped to assert the continued primacy of human decision-making in an otherwise automatable context. It also did organizational work when the project manager himself refused to get the joke: "I don't know Hal," he reportedly said, "but there are lots of people I'd like to send to Europa" (October 17, 2016; reported via email). This reinforced the manager's position with respect to his team, while also motivating team members to work hard lest they become the person that their manager wishes to send on an interplanetary cruise.

Another example is especially evocative of the "action orientation" implied by folk fictions as sense-making devices. When mission leaders were called to a meeting at NASA Headquarters to make a very difficult decision that would affect the future of their mission, the mood on the project was tense. Going into this meeting, a team leader had increasing concerns about its prospective outcomes. He was hopeful that the group would come to agreement, but there were so many competing needs and ideas, and so much at stake, that he could not foresee a happy resolution. A week before the meeting, he began to call the impending event a "Kobayashi Maru test." This is a reference to a scene in Star Trek II: The Wrath of Khan, where new Starfleet recruits participate in a simulation where they are faced with a choice about rescuing a Federation ship in Klingon territory. Abandon the ship and all aboard will die; try to save it and the Klingons will declare war. The Kobayashi Maru test is therefore described as "a test of character" in the face of a "no-win scenario," to see how would-be leaders behave "in the face of death" (Meyer 1982). The reference spoke to the sense of dread and no-win outcomes associated with the meeting. But it also suggested a way forward. It is well known among Trek aficionados that Captain Kirk was the only recruit to pass the Kobayashi Maru test: by reprogramming the simulation so that there was a win condition. This reference was not lost among those with whom the scientist shared his appraisal of the situation. Upon framing the upcoming event in this way, he began working assiduously behind the scenes to avoid a dreaded "no-win situation" for all involved. 


\section{Folk Fictions and Social Problems}

Many members of NASA's mission to Europa were inspired by the vision of humans in space as pictured in Star Trek, Star Wars, and 2001: A Space Odyssey. But the vision of life in space shown in these series is too distant from contemporary reality for immediate gratification. Science fiction does not serve as a way of explaining or framing their scientific work (Milburn 2008); nor are these individuals responsible for creating future imaginaries as "visioneers" or science advisors. They do not use these narratives to efface the organization and embrace its dynamics as personal failures or successes (Mirmalek 2009). Instead, invoking science fiction as folk fiction makes social and political undercurrents visible. It therefore that accomplishes various forms of organizational and members' work for mission teammates as they con technoscientific problems.

For instance, science fiction references forge a sense of group membership through shared cultural codes and ties. Folk fictions are a form of members' talk that circumscribes belonging, delineating those who are true planetary scientists from those who do not know the field's shared cultural codes (people who, for instance, do not know when they book a pod at a conference labeled "Wrath of Khan" that they should occupy the second pod in the row). Folk fictions may also assert boundaries between missions based on which science fiction pieces are most often invoked in as commentary on events. This dual use of science fiction references may explain why occasional reference to Star Wars or Doctor Who were not entirely out of place among Europa team members, as they would still satisfy the first category if not the second. It also points to a way in which, consistent with Burri's analysis of boundary work among radiologists, drawing distinctions can be a way of managing symbolic capital internal to the field (Burri 2008). While I did not note science fiction quotes used to assert social status, as in other geek communities (Dunbar-Hester 2008), expectations for engagement certainly required considerable fluency to recognize and deploy such symbols, limiting membership and participation (Traweek 1988).

Boundary work is not just about exclusions, but about inclusions as well. To that end shared science fiction touchstones are especially important for uniting team members on new projects-like the Europa mission-who have previously worked on other teams under different organizational and operational paradigms. For instance, a few scientists and engineers served on the smaller, more focused and inexpensive Mars missions like Phoenix, MER, or Pathfinder; many more worked on expansive and large projects like Cassini, Galileo, or Curiosity; still others worked on comparatively small teams like Dawn, MESSENGER, or Lunar Reconnaissance Orbiter. The scientists in the room are also in frequent competition for funding to explore specific moons or planets, with limited resources to do so, and with applications under development with or under simultaneous review by their mission peers. Reference to science fiction therefore provides a shared heritage as well as trajectory among everyone in the room. Everyone is working toward the eventual human exploration of the universe, and the lessons learned on Star Trek or in 2001 provide a shared background in the face of heterogeneous mission experiences. Appeals to these series therefore use a common reference point to build solidarity and to solve problems as the team forms.

Above all, folk fictions are ready-to-hand resources for resolving problems that involve people and politics alongside scientific and technical issues. As such they provide a local expert vocabulary for doing lay STS: identifying and commenting upon sociotechnical tensions, all the 
while maintaining ironic distance and a sense of group membership. NASA scientists are no strangers to politics, as their work is constantly subject to congressional whims and shifting administrative priorities from Washington. But it is less straightforward to discuss the micropolitics of the field as well: persistent inequalities, interinstitutional misunderstandings, and the competition for resources. The scientists and engineers I observed did not wish to be overly swayed by such considerations, but they could not hope to be successful if they turned a blind eye. Whether due to the norms of the community (Merton 1942) or efforts to bound scientific expertise in public debate (Gieryn 1999; Jasanoff 1987), they sought to skirt the line as responsible and disinterested actors while wielding enough knowledge of political undercurrents to be effective. Their typical career trajectory is devoid of formal training in ethics, sociology, or politics, or even in the more quotidian practices essential to lab management such as leadership, decision-making, and organizational behavior--training that might otherwise provide individuals with an expert vocabulary for analyzing social situations and repertoires for taking well-considered action. Planetary scientists therefore deploy science fiction narratives in much the same way that nuclear physicists develop cultural codes to mitigate the moral and political landscape of their work (Gusterson 1996) and ecologists appeal to funding demands or to the norms of science to refer to the boundaries of science and politics (Kinchy and Kleinman 2003). Such studies remind us that work and talk at the intersection of "science" and "politics" need not necessarily be strategic (Gieryn 1999), but may rather reflect and reproduce boundaries that local actors know to be unclear, unsteady, and shifting, especially in uncertain or controversial times.

Folk fictions, then, fill a void as an expert form of talk that can elliptically refer to delicate social relations in the room, for those in the know. The lander team that should "attempt no landing there," Major Kong's potential inadvertent destruction of local goals, and the Kobayashi Maru meeting that must be reprogrammed all speak to social and political complexities that individuals navigate in their daily work. This does not mean that the gap between the social and the scientific closes for these practitioners, or that it is safe to be overtly political about one's science. Folk fictions instead achieve the careful balancing act of producing ironic commentary that preserves the individual's distance from the situation at hand (Goffman 1961), while at the same time asserting membership with the broader group by virtue of demonstrated cultural fluency. Recall how the scientist's reference to ion drives that earned a laugh among his new colleagues built solidarity in the room by virtue of how it allowed everyone to distance themselves from the inter-center politics inherent in propulsion development. This ultimately enables mission members to preserve face (Goffman 1959) in encounters that might otherwise place them directly in the line of accusation of negative political or social interventions in their work.

I suggest, then, that we address science fiction and other folk fictions in scientific sites as a form of "ethnomethod": a members' technique of sense-making that is part of the "ongoing achievement of the organized activities of everyday life" (Garfinkel 1967: 34). In his discussion of lay sociologizing, Harold Garfinkel (1967) argues that communities have their own explanations for social facts and "common sense knowledge of social structure" (Garfinkel 1967: 77) that the analyst must take seriously, especially as these evade or challenge the pre-existing categories of formal analysis. While folk theories derive their analytical power from anthropological notions of 
folk classifications and cultural knowledges, analyzing folk fictions requires that we shift our attention to the micro-scale. As a ready-to-hand resource for sense-making, folk fictions are common-sense, reflexive guides for rational action, ordering, and explanation that draw on preexisting stories that "Anyone Like Us Necessarily Knows" (Garfinkel 1967: 54). Their invocation is a meaningful, indexical action undertaken by members to make local social problems accountable and available for practical interaction. At once authentic and ironic, these vocabularies enable membership at the same time as social commentary, role embracement at the same time as role distancing. As analysts, we must be attentive to these forms of talk as lay expert techniques for sociotechnical sense-making and local ordering, especially as they diverge from other forms of expert talk on these topics in, say, the pages of the Harvard Business Review or in STS journals.

This role for science fiction in lay theorizing is also generative for STS scholars who intervene in their sites of study. Toward the end of my fieldwork, as I began to articulate this role for science fiction through analyzing my fieldnotes and reflecting upon my experiences, I found that these folk fictions were an effective way to communicate my own work to the scientists and engineers around me. For instance, two young engineers caught between two significant units in the mission organization asked for my assistance in their project. They had ambitious goals to implement a new system to help the mission, but were encountering resistance to their ideas from both scientists and engineers. Reaching for STS literature to illuminate their situation, I explained "boundary objects" and "trading zones" (Star and Griesemer 1998; Galison 1998); when that elicited blank stares I turned to the sociology of brokerage and "structural holes" (Burt 2004). They were politely interested but confused as to how this could help them. Finally, in a conversation with one of them, I used a Star Trek analogy: "It's like you've been called into the Neutral Zone to negotiate a peace treaty between the Klingons and the Federation, and you think it's actually neutral, but there's hundreds of years of conflicts built up on both sides, so you have to acknowledge and work around those misunderstandings before you can build anything new." Instantly, the young engineer's eyes brightened. "That's exactly what it's like!" she exclaimed. The analogy gave her and her colleague new ideas about how to move forward.

\section{Conclusion}

Following "science fiction at the bench," as Colin Milburn suggests we do, gives us a way of tracing how scientists negotiate membership, manage social capital and save face within environments suffused with sociopolitics. Recognizing contextual science fiction references as a form of folk fiction offers a new contribution to our understanding of how science fiction as a cultural commodity animates the local contexts of technoscience. Folk fictions are at the same time narrative, proscriptive, and reflexive. Reference to them reinforces a sense of team identity and solidarity even as it asserts local legitimate membership and cultural fluency. It also enables scientists and engineers to step outside of prescribed roles and the task at hand to provide commentary on and direction for their technoscientific organization. Making overt references to these commonly known materials as a form of ethnomethod can provide role distance while at the same time affirm membership, enable commentary, make sense of sociotechnical complexity and 
suggest a course of action to address the difficulties of the situation at hand, all the while sheltering scientists from accusations that their decisions are politically or relationally motivated. In this way, certain shared science fictions are mobilized on the ground as folk fictions to solve problems as the team constructs their spacecraft and the future of their science. As the case of the neutral zone suggests, too, it can provide a helpful shorthand for communicating sociological ideas to scientific communities.

Lay sociology and social theorizing may not always be conducted using science fiction. Community members in other sites may reach for other pre-existing popular narratives to identify and navigate the political tensions in their work, to articulate the managerial, interpersonal, and workplace tensions and trade-offs associated in the human side of science and engineering, as well as to tie technical questions on the micro level to macro political concerns and national priorities. This field site at NASA has a predilection, perhaps unsurprisingly, for space and Cold War dramas to describe their work: other sites may prefer other fictions. Regardless, the ironic commentary offered by shared science fiction universes in everyday expert conversation gives STS scholars another way to observe communities, politics, and legitimacy work in action, even as scientists address the local tensions of making fictional futures into science fact.

\section{Author Biography}

Janet Vertesi is a sociologist of science and technology at Princeton University who has studied planetary scientists on NASA's robotic spacecraft teams since 2005. She holds a Ph.D. in Science \& Technology Studies from Cornell University and an MPhil in History and Philosophy of Science from Cambridge University. Her first book, Seeing Like a Rover (Chicago, 2015) examines image processing practices on the Mars Exploration Rover mission; she is also co-editor of digitalSTS and Representation in Scientific Practice Revisited.

\section{Acknowledgements}

This work was supported by the National Science Foundation under Grant \#1552469. Many thanks to the Europa Clipper Mission Team, especially Robert Pappalardo at the Jet Propulsion Laboratory, for permission to study their mission, to the manuscript's reviewers, and to Ingrid Ockert and Jordan Bimm for their comments on earlier drafts.

\section{References}

Balsamo, Anne. 1996. Technologies of the Gendered Body: Reading Cyborg Women. Durham: Duke University Press.

Benjamin, Ruha. 2011. “Organized Ambivalence: When Sickle Cell Disease and Stem Cell Research

$\begin{array}{llllll}\text { Converge." Ethnicity } \mathcal{E} & \text { Health } & 16 & (4-5): & 447-63 .\end{array}$

https: / / doi.org/10.1080/13557858.2011.552710. 
__ 2016. "Racial Fictions, Biological Facts: Expanding the Sociological Imagination through Speculative Methods." Catalyst: Feminism, Theory,Technoscience 2 (2): 1-28.

—_. 2018. "Prophets and Profits of Racial Science." Kalfou 5 (1). https: / / doi.org/10.15367/kf.v5i1.198.

Burri, Regula Valérie. 2008. "Doing Distinctions: Boundary Work and Symbolic Capital in Radiology." Social Studies of Science 38 (1): 35-62. https: / / doi.org/10.1177/0306312707082021.

Burt, Ron S. 2004. "Structural Holes and Good Ideas." American Journal of Sociology 110 (2): 349-99.

Clarke, Arthur C, and Stanley Kubrick. 1968. 2001, a Space Odyssey. New York: The New American Library.

Collins, Harry M., and Robert Evans. 2002. "The Third Wave of Science Studies: Studies of Expertise and Experience." Social Studies of Science 32 (2): 235-96. https: / / doi.org/10.1177/0306312702032002003.

Collins, Randall. 2004. Interaction Ritual Chains. Princeton Studies in Cultural Sociology. Princeton, N.J: Princeton University Press.

Coulon, Alain. 1995. Ethnomethodology. 2455 Teller Road, Thousand Oaks California 91320 United States of America: SAGE Publications, Inc. https:/ / doi.org/10.4135/9781412984126.

Dourish, Paul, and Genevieve Bell. 2014. "'Resistance Is Futile': Reading Science Fiction alongside Ubiquitous Computing." Personal and Ubiquitous Computing 18 (4): 769-78. https: / / doi.org/10.1007/ s00779-013-0678-7.

Dunbar-Hester, Christina. 2008. "Geeks, Meta-Geeks, and Gender Trouble: Activism, Identity, and Low-Power FM Radio." Social Studies of Science 38 (2): 201-32.

Edwards, Paul N. 1997. The Closed World: Computers and the Politics of Discourse in Cold War America. First MIT Pr. Paperb. ed. Inside Technology. Cambridge, Mass. ;London: MIT.

Epstein, Steven. 2007. Inclusion: The Politics of Difference in Medical Research. Chicago Studies in Practices of Meaning. Chicago: University of Chicago Press.

Galison, Peter. 1998. “Trading Zone: Coordinating Action and Belief." In The Science Studies Reader, edited by Mario Biagioli, 137-60. New York: Routeledge.

Garfinkel, Harold. 1967. Studies in Ethnomethodology. New Jersey: Prentice Hall.

Garfinkel, Harold, Michael Lynch, and E Livingston. 1981. "The Work of a Discovering Science Construed with Materials from the Optically Discovered Pulsar." Philosophy of Social Science 11: 121-58.

Gieryn, Thomas F. 1999. Cultural Boundaries of Science: Credibility on the Line. Chicago: University of Chicago Press.

Goffman, Erving. 1959. The Presentation of Self in Everyday Life. New York: Doublesday.

—_ 1961. Encounters: Two Studies in the Sociology of Interaction. Hammondsworth, Middlesex: Penguin Press.

Goodwin, Barbara. 1988. "Science-fiction Utopias." Science as Culture 1 (2): 107-19. https: / / doi.org/10.1080/09505438809526202.

Gusterson, Hugh. 1996. Nuclear Rites: A Weapons Laboratory at the End of the Cold War. Berkeley: University of California Press. 
Haraway, Donna J. 1991. Simians, Cyborgs, and Women. New York: Routeledge.

Hayles, N. Katherine. 1999. How We Became Posthuman: Virtual Bodies in Cybernetics, Literature, and Informatics. University Of Chicago Press.

Hecht, Gabrielle. 1998. The Radiance of France: Nuclear Power and National Identity after World War II. Inside Technology. Cambridge, Mass: MIT Press.

Helmreich, Stefan. 2009. Alien Ocean. Cambridge MA: MIT Press.

Hyams, Peter. 1984. 2010: The Year We Make Contact. Metro-Goldwyn-Mayer.

Jameson, Fredric. 2005. Archaeologies of the Future: The Desire Called Utopia and Other Science Fictions. London.

Jasanoff, Sheila. 1987. “Contested Boundaries in Policy-Relevant Science." Social Studies of Science 17 (2): 195-230.

Jasanoff, Sheila, and Sang-Hyun Kim, eds. 2015. Dreamscapes of Modernity: Sociotechnical Imaginaries and the Fabrication of Power. Chicago ; London: The University of Chicago Press.

Kinchy, Abby J., and Daniel Lee Kleinman. 2003. "Organizing Credibility: Discursive and Organizational Orthodoxy on the Borders of Ecology and Politics." Social Studies of Science 33 (6): 869-96. https: / / doi.org/10.1177 / 0306312703336003.

Kirby, David. 2010. “The Future Is Now: Diegetic Prototypes and the Role of Popular Films in Generating Real-World Technological Development." Social Studies of Science 40 (1): 41-70.

Kirby, David A. 2011. Lab Coats in Hollywood: Science, Scientists, and Cinema. Cambridge, Mass: MIT Press.

Kubrick, Stanley. 1964. Dr. Strangelove: Or, How I Learned to Stop Worrying and Love the Bomb. Columbia Pictures.

—_. 1968. 2001: A Space Odyssey. Metro-Goldwyn-Mayer.

Lynch, Michael. 1993. Scientific Practice and Ordinary Action: Ethnomethodology and Social Studies of Science. Cambridge [England]; New York: Cambridge University Press.

McCain, Jessica, Brittany Gentile, and W. Keith Campbell. 2015. "A Psychological Exploration of Engagement in Geek Culture: E0142200." PLoS One 10 (11). http:/ / dx.doi.org.ezproxy.princeton.edu/10.1371/journal.pone.0142200.

McCray, W. Patrick. 2012. The Visioneers: How a Group of Elite Scientists Pursued Space Colonies, Nanotechnologies, and a Limitless Future. Princeton: Princeton University Press.

McCurdy, Howard E. 1994. Inside NASA: High Technology and Organizational Change in the U.S. Space Program. The Johns Hopkins University Press.

Merton, Robert. 1942. “The Normative Structure of Science." In The Sociology of Science: Theoretical and Empirical Investigations, edited by Norman W Storer, 1. Sociology of Science in Europe:267-78. Chicago: University of Chicago Press.

Meyer, Nicholas. 1982. Star Trek II: The Wrath of Khan. Paramount Pictures.

Milburn, Colin. 2008. Nanovision: Engineering the Future. Durham: Duke University Press.

—_. 2010. "Modifiable Futures: Science Fiction at the Bench." Isis 101 (3): 560-69. https: / / doi.org/10.1086/ 655793. 
Mirmalek, Zara. 2009. "Dreaming of Space, Imagining Membership: The Work Conduct of Heroes." Management \& Organizational History 4 (3): 299-315. https: / / doi.org/10.1177/1744935909337753.

Nimoy, Leonard. 1984. Star Trek III: The Search for Spock. Paramount Pictures.

O'Connor, Mike. 2012. "Liberals in Space: The 1960s Politics of Star Trek." The Sixties 5 (2): 185-203. https: / / doi.org/10.1080/17541328.2012.721584.

Penley, Constance. 1997. NASA/TREK: Popular Science and Sex in America. New York: Verso.

Prior, Lindsay. 2003. "Belief, Knowledge and Expertise: The Emergence of the Lay Expert in Medical Sociology: Belief, Knowledge and Expertise." Sociology of Health \& Illness 25 (3): 41-57. https:/ / doi.org/10.1111/1467-9566.00339.

Rip, Arie. 2006. "Folk Theories of Nanotechnologists." Science as Culture 15 (4): 349-65. https: / / doi.org/10.1080/09505430601022676.

Shaw, Debra Benita. 2000. Women, Science, and Fiction: The Frankenstein Inheritance. Houndmills, Basingstoke, Hampshire: New York: Palgrave.

Shilton, K. 2013. "Values Levers: Building Ethics into Design." Science, Technology \& Human Values 38 (3): 374-97. https: / / doi.org/10.1177 / 0162243912436985.

Simakova, Elena. 2012. "Collaboration Talk: The Folk Theories of Nano Research." Science as Culture 21 (2): 177-203. https: / / doi.org/10.1080/09505431.2011.613990.

Stanley, John D. 1966. "Fictions: Legal and Organizational." Academy of Management Journal 9 (2): 123-26. https: / / doi.org/10.5465/255030.

Star, Susan Leigh, and James R Griesemer. 1998. “Institutional Ecology, 'Translations,' and Boundary Objects: Amateurs and Professionals in Berkeley's Museum of Vertebrate Zoology, 1907-39." In The Science Studies Reader, edited by Mario Biagioli, 505-24. New York: Routeledge.

Steen, M. 2015. "Upon Opening the Black Box and Finding It Full: Exploring the Ethics in Design Practices." Science, Technology \& Human Values 40 (3): 389-420. https: / / doi.org/10.1177/0162243914547645.

Swidler, Ann. 1986. "Culture in Action: Symbols and Strategies." American Sociological Review 51 (2): 273. https:/ / doi.org/10.2307/2095521.

Traweek, Sharon. 1988. Beamtimes and Lifetimes: The World of High Energy Physicists. Cambridge, MA: Harvard University Press.

Varma, Roli. 2007. "Women in Computing: The Role of Geek Culture." Science as Culture 16 (4): 359-76. https: / / doi.org/10.1080/09505430701706707.

Vaughan, Diane. 1997. The Challenger Launch Decision: Risky Technology, Culture, and Deviance at NASA. 1st ed. University Of Chicago Press.

Vertesi, Janet. 2015. Seeing like a Rover: How Robots, Teams, and Images Craft Knowledge of Mars. Chicago ; London: The University of Chicago Press.

- 2020. The Social Life of Spacecraft. Chicago: The University of Chicago Press.

Wynne, Brian. 1992. "Misunderstanding Misunderstanding: Social Identities and Public Uptake of Science." Public Understanding of Science 1 (3): 281-304. 